\title{
Análise geoquímica e ambiental para descrição da Bacia do Rio Oratórios (MG)
}

\section{Frederico Melo Lacerda ${ }^{1 *}$ \\ Hubert Mathias Peter Roeser ${ }^{2}$}

${ }^{1}$ Faculdades Integradas Pitágoras - Montes Claros (MG), Brasil.

${ }^{2}$ Universidade Federal de Ouro Preto - Ouro Preto (MG), Brasil.

*Autor correspondente: fredericolac@hotmail.com

\section{Resumo}

O Brasil precisa cada vez mais de experiências e metodologias que auxiliem no diagnóstico de bacias hidrográficas. Ter exemplos de estudos e diagnósticos cria um leque de experiências que podem ser usadas como guias para as demais regiões do Brasil. No presente estudo foi feito um diagnóstico da microbacia do Rio Oratórios, inserida na Bacia do Rio Doce, atendendo às cidades de Amparo do Serra, Oratórios e Ponte Nova, em Minas Gerais. Foram realizadas quatro campanhas de amostragem de água, distribuídas nas estações chuvosas e secas, ao longo do Rio Oratórios, e alguns dos tributários dos rios. Ao empregar a classificação segundo os fatores (ou mecanismos) ambientais que afetam a química de suas águas constata-se que o Rio Oratórios é controlado em sua composição principalmente pelo seu ambiente litológico. Como valores de referência, seguiram-se as resoluções CONAMA 357/2005 e 430/2011. Pelas características físico-químicos e biológicas medidas, constataram-se diversos valores que não respeitavam a legislação pertinente, como, por exemplo, valores elevados de ferro, manganês, de alumínio, coliformes termotolerantes e Demanda Química de Oxigênio (DQO), classificando o Rio Oratórios em classe inferior a 2 e tornando-o impróprio para uso direto, sem tratamento adequado. Assim, torna-se necessária a implementação de um plano de uso dos recursos hídricos para melhor aproveitamento da bacia, situação semelhante em diversas bacias hidrográficas brasileiras. Palavras-chave: Rio Oratórios, recursos hídricos, saneamento, geoquímica ambiental, diagnóstico ambiental.
Abstract
Brazil needs increasingly of experiences and methodologies that help the diagnostic of watersheds. Examples of studies and diagnostics create a variety of experiences that can be used like guides to other Brazilian regions. In this study it was done a diagnostic of watershed of Oratórios River, on Doce River's Watershed, serving the cities of Amparo do Serra, Oratórios and Ponte Nova, in Minas Gerais. Four water sampling campaigns, distri- buted in rain season and dry season throughout of Oratórios River, and some of his tributaries were done. By employing classification according to the factors (or mechanisms) Environmental affecting the chemistry of the water can be seen that the Oratórios River is controlled in their composition mainly for their lithological environment. As reference values, followed by the CONAMA 357/2005 and 430/2011. The physical, chemical and biolo- 
gical characteristics measured were noted many values that did not comply with the relevant legislation, for example, high levels of iron, manganese, aluminum, fecal coliform and Chemical Oxygen Demand (COD), ranking in Oratórios Rivers class less than 2 and making it unsuitable for direct use without proper treatment. Thus, it becomes necessary to implement a use plan of water resources for better utilization of the basin, similar situation in several Brazilian basins.

Keywords: Rio Oratórios, hydric resources, sanitation, environmental geochemistry, environmental diagnosis.

\section{INTRODUÇÃO}

Sabemos que o planeta o qual habitamos tem aproximadamente $70 \%$ de sua superfície coberta por água. Entretanto, desse largo potencial hídrico, apenas $3 \%$ é doce. Por conseguinte, a quantidade para o consumo humano, potável e disponível, representa apenas $0,03 \%$ desse total (SANASA 2013). Analisando este cenário, podemos considerar o Brasil um país privilegiado, uma vez que, em seu território, há cerca de $14 \%$ de toda a água potável disponível do mundo, embora esta distribuição não ocorra de forma homogênea, já que $73 \%$ da água disponível para o consumo encontra-se na região Norte, zona menos industrializada e povoada da nação. Aos demais centros sobram apenas $27 \%$ da capacidade hídrica do país (Benevides \& Beekman 1995, Setti \& Lima 2001, Brasil 2006).

A água é um elemento imprescindível à vida. Tanto as superficiais quanto as subterrâneas devem ser preservadas da contaminação. Portanto, qualquer diminuição importante do nível de qualidade e/ou quantidade de uma água corrente ou represada acomete o risco de torná-la nociva para todo ser vivo (Derísio 2000). Em linhas gerais, importa-nos dizer que o descaso com a qualidade da água significa também descaso com o ser humano e com os demais seres vivos que dela dependem para sobreviver.

Os problemas de escassez hídrica decorrem da combinação do crescimento exagerado das demandas e da degradação da qualidade, principalmente a partir da década de 1950, com a aceleração do processo de urbanização, industrialização e expansão agrícola (Faria 2004).

Durante muito tempo, a ideia de abundância serviu de suporte à cultura do desperdício de água, dando subsídio à não realização de investimentos necessários para o uso e proteção mais eficientes. $\mathrm{O}$ consumo adequado dos recursos naturais, principalmente dos hídricos, atualmente vem sendo considerado de suma importância, pois a água está presente em toda a biosfera: nos corpos d'água, no ar, no solo, subsolo e nos seres vivos, desempenhando considerável função em quase todas as atividades humanas, econômicas, sociais, culturais e religiosas (Feldmann 1992).

O gerenciamento dos recursos hídricos realiza o desafio de minimizar os impactos negativos causados pelas ações antropogênicas e naturais a fim de equacionar os problemas existentes e gerar melhores situações de uso. Para isso, são necessários trabalhos de sensibilização e conscientização acerca da necessidade de se preservar este bem, que é vital à sobrevivência dos seres vivos (Setti \& Lima 2001).

Com essa nova perspectiva, inserimos a caracterização da Bacia do Rio Oratórios, em Minas Gerais, em seus aspectos demográficos, geográficos, econômicos, políticos, sociais e ambientais, pois, apesar de não ser o foco deste trabalho, por meio de análises como estas será possível obter melhor compreensão da situação atual dessa bacia e relacionar os resultados físico-químicos e biológicos no contexto local. Além disso, para a elaboração desse diagnóstico ambiental, utilizamos a caracterização e análise do uso e ocupação do solo já realizadas por outros autores e em outras bacias hidrográficas (Lougon 2009, Soares 2011, Romão 2011).

$\mathrm{Na}$ região de Ouro Preto e Mariana (MG), na Bacia Hidrográfica do Rio Doce, trabalhos geoquímicos ambientais mais detalhados começaram a ser realizados a partir da década de 1980 com o objetivo de se conhecer a contaminação por metais pesados, principalmente mercúrio, produto intensamente utilizado por garimpeiros de toda a região para o beneficiamento do ouro (Cruz 2002). De acordo com o Ministério do Meio Ambiente, o Instituto Mineiro de Gestão das Águas e o Comitê de Bacia Hidrográfica do Rio Doce, a região da Bacia Hidrográfica do Rio Piranga apresenta economia bem diversificada, baseada principalmente na mineração e na agropecuária.

A análise da Bacia Hidrográfica do Rio Oratórios é relevante porque este rio, um dos tributários do Rio Piranga, afluente do Rio Doce, ainda é pouco estudado e de grande importância para a região. Ao propormos a sua caracterização e diagnóstico ambiental, acreditamos que alcançaríamos uma visão proativa para a região, afinal, tendo em mãos um conhecimento mais pormenorizado do local, é possível realizar ações ambientais com finalidades preventivas ao invés de buscarmos apenas medidas corretivas.

Em suma, este trabalho procura caracterizar e diagnosticar a Bacia Hidrográfica do Rio Oratórios visando conhecer o nível da qualidade de seus recursos hídricos por meio de análises físico-químicas, químicas e microbiológicas em amostras de água e sedimentos. Além disso, o permite questionar a origem dos problemas ambientais e a influência deles no meio ambiente, bem como propor alternativas viáveis de solução para os prováveis problemas a serem encontrados. 


\section{METODOLOGIA}

As metodologias aplicadas durante esta pesquisa podem ser separadas em três grupos: trabalhos realizados no campo, trabalhos realizados nos laboratórios e trabalhos de pesquisas bibliográficas.

Fazem parte dos trabalhos de campo as amostragens e as medidas físico-químicas: $\mathrm{pH}$, temperatura, oxigênio dissolvido, condutividade elétrica, resistividade, sólidos totais dissolvidos (STD), potencial de oxidação e redução (POR) e turbidez. Nos laboratório foram realizadas as preparações de todas as amostras, além das análises químicas de alcalinidade, sulfato, cloro e biológicas, determinação do número mais provável de organismos indicadores de contaminação fecais recente e, por fim, análises dos elementos metálicos tanto das águas quanto dos sedimentos. Os trabalhos bibliográficos caracterizaram a Bacia

\section{1. Área de estudo}

A Bacia do Rio Oratórios está inserida na Bacia Hidrográfica do Rio Doce, na sub-Bacia do Rio Piranga DO1, contida nos municípios de Amparo do Serra, Oratórios e Ponte Nova, conforme Figura 1. Segundo o Instituto Brasileiro de Geografia e Estatística e a Associação Mineira de Municípios, as três cidades conta com população total de cerca de 65,3 mil habitantes e abrangem área de $705,3 \mathrm{~km}^{2}$.

Segundo dados do Comitê de Bacia Hidrográficas do Rio Doce e do Comitê da Bacia Hidrográfica do Rio Piranga, divulgados por Lacerda (2010), a altitude na região varia de $380 \mathrm{~m}$ na foz, em Ponte Nova, a $650 \mathrm{~m}$, próximo às nascentes, em Amparo do Serra. Já o clima, segundo a classificação de Köppen (Boletim Pluviométrico da Bacia do Rio Doce do Departamento Nacional de Água e Energia Elétrica - DNAEE) identifica, basicamente,
Hidrográfica do Rio Oratórios em seus aspectos demográficos, geográficos, econômicos, políticos, sociais e ambientais.

Quatro campanhas de amostragem de água e sedimentos foram realizadas e distribuídas no período de 2011 a 2012, nas estações verão (chuvoso) e inverno (seco), ao longo do Rio Oratórios e em alguns de seus tributários. Ao adotar essa forma de distribuição das amostragens, procura-se minimizar as interferências das diferentes épocas climáticas nos resultados. Os sítios de amostragem foram definidos por meio de visitas à área de estudo, de acordo com condições favoráveis à coleta e levando-se em conta a sua distribuição geográfica, para que os resultados fossem representativos. Foram determinados 13 sítios de amostragem, sendo 9 ao longo do Rio Oratórios e 4 em alguns de seus tributários.

clima tropical, com estações bem definidas: no verão, temperaturas mais elevadas e chuvas; e no inverno, temperaturas mais baixas e tempo mais seco. A temperatura média é de cerca de $20^{\circ} \mathrm{C}$, e os valores de precipitações anuais podem atingir a ordem de $1.500 \mathrm{~mm}$. Além disso, há predominância de latossolos amarelos e podzólicos vermelho-escuro em quase toda a área, e focos erosivos em toda bacia.

Considerando o meio biótico, a região do Rio Oratórios foi intensamente ocupada nos últimos anos, o que levou à perda de grande parte da sua cobertura vegetal original e, consequente, alteração do meio biótico. A vegetação original tem perdido cada vez mais espaço para a monocultura, intensificando a diminuição e/ou redução de espécies de animais e vegetais nativos.

Figura 1

Localização da Bacia do Rio Oratórios em relação à Bacia do Rio Doce.

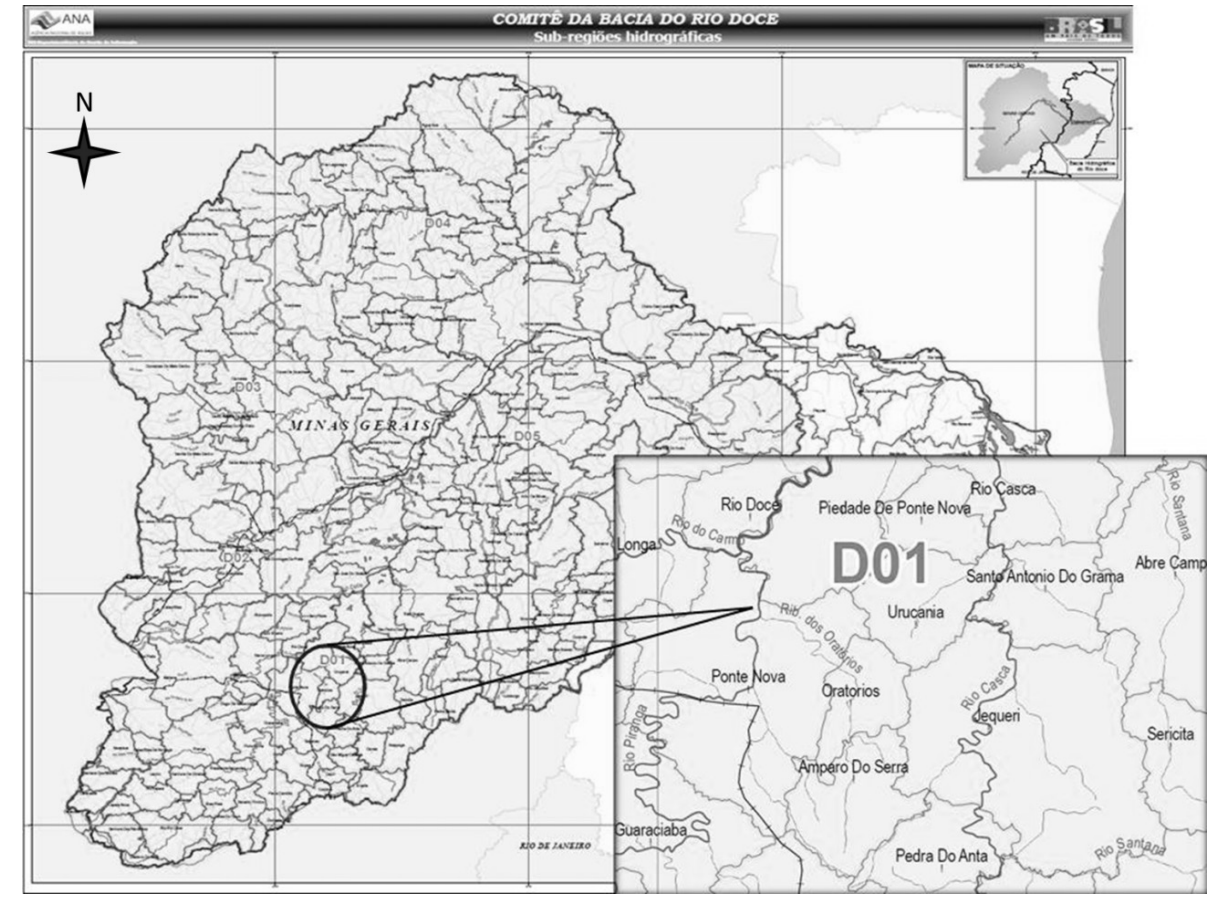

Modificado de ANA, Brasil (2006) (mapa sem escala). 
A economia da área de estudo é diversificada, podendo se destacar: silvicultura com eucalipto, atividade canavieira associada à agroindústria sucroalcooleira (principalmente

\subsection{Amostragens das águas}

No laboratório, os frascos plásticos de 60 e $1.000 \mathrm{~mL}$ utilizados para a coleta de água, além do recipiente para análises biológicas, foram separados e preparados na véspera da realização do trabalho de campo. As amostras de água foram coletadas de acordo com a metodologia proposta por Agudo (1987), sempre antes da amostra de sedimento, para evitar excesso de sólidos em suspensão. As coletas foram realizadas contra a corrente, fazendo-se ambiente com a água do rio.

Dois tipos de amostradores foram utilizados, dependendo da facilidade de coleta. Nas áreas em que o acesso era suspenso (caracterizado pela presença de ponte), foi utilizado um balde amarrado a uma corda. Onde o acesso era possível pela margem do rio, usou-se um frasco com capacidade de $2 \mathrm{~L}$, acoplado a uma haste ou, novamente, apenas o balde.

Durante as coletas em cada sítio foram realizadas:

\subsection{Amostragens dos sedimentos}

Entende-se por sedimentos os materiais insolúveis depositados no fundo dos corpos de água. Os sedimentos constituem um fator muito importante do sistema aquático por sua participação no equilíbrio dos poluentes solúveis/ insolúveis e sua maior permanência no corpo de água, sendo, em geral, integradores das cargas poluentes recebidas (Agudo 1987).

Geralmente os sedimentos de interesse ambiental são aqueles que permanecem nas camadas superficiais e

\subsection{Medições in situ}

No local da coleta, foram determinados os seguintes parâmetros: oxigênio dissolvido (OD), temperatura, $\mathrm{pH}$, condutividade elétrica, STD, POR e turbidez.

\subsection{Análises das amostras no laboratório}

No Laboratório de Saneamento Ambiental da Escola de Minas da Universidade Federal de Ouro Preto (UFOP) foram realizadas as determinações de cloreto por meio da técnica titulométrica, do sulfato pelo método turbidimétri-

\subsection{Análise química}

Teores de metais e metaloides foram determinados por Espectrofotômetro de Emissão Atômica com Fonte de Plasma Indutivamente Acoplado (ICP-EOS), em operação no Laboratório de Geoquímica Ambiental (LGqA) do pequenos alambiques), agricultura de subsistência, pecuária extensiva (leite e corte) e suinocultura intensiva, pequenos garimpos e indústrias principalmente alimentícias.
- análises em campo: $\mathrm{pH}$, temperatura, oxigênio dissolvido, condutividade elétrica, resistividade, sólidos totais dissolvidos (TDS), potencial de oxidação e redução (ORP) e turbidez;

- coleta de amostra em frascos de $1.000 \mathrm{~mL}$ para a determinação dos teores de sulfato, alcalinidade e cloro;

- coleta de amostra em frascos de $60 \mathrm{~mL}$ para determinação de metais principais e traços pela Espectrometria de Emissão Atômica, passando ainda em campo pelo processo de filtração e utilizando seringa e membranas de filtro de $0,45 \mu \mathrm{m}$ de porosidade. Em seguida foi acidificada com ácido nítrico concentrado $\left(\mathrm{HNO}_{3} 65 \%\right)$ em $\mathrm{pH}<2$ (Greenberg et al. 1992);

- coleta em recipientes próprios para análises microbiológicas.

As amostras de água foram identificadas com as letras FLRO e o número do sítio de amostragem.

estão finamente divididos (fração $<200 \mu \mathrm{m}$ ). Assim, em muitos casos a retirada de alguns centímetros da camada superficial basta para atender à maioria dos estudos (Agudo 1987).

Os sacos plásticos utilizados para a coleta de sedimentos, e os amostradores foram preparados e separados na véspera da realização do trabalho de campo. Os procedimentos de coleta dos sedimentos variam em cada sítio, de acordo com as condições de acesso aos locais.

$\mathrm{Na}$ determinação dos parâmetros $\mathrm{OD}$ e temperatura foi utilizado um oxímetro; na do $\mathrm{pH}$, condutividade elétrica, STD e POR, sonda multiparamétrica; e na de turbidez, um turbidímetro.

co e da alcalinidade pelo Procedimento Operacional Padrão do laboratório, todas baseadas nas metodologias propostas por Greenberg et al. (1992), no Standard methods for examination of water and wastewater.

Departamento de Geologia (DEGEO) da UFOP.

O método analítico por ICP-OES é uma técnica de espectrometria de emissão que explora o fato de os elétrons excitados emitirem energia a um determinado comprimento 
de onda quando retornam ao estado fundamental. A característica principal deste processo é a emissão de energia em comprimentos de onda específicos para cada elemento. Embora cada

\subsection{Análise microbiológica}

Para análises microbiológicas foi utilizado o sistema Colilert 24 horas (IDEXX-USA) na determinação do número mais provável de coliformes totais e E. coli, seguindo procedimento padrão do laboratório de Qualidade de Águas - LaQua, da Escola de Farmácia da UFOP.

O Colilert utiliza tecnologia de substrato definido [Defined Substrate Technology $\left.{ }^{\circledR}\left(\mathrm{DST}^{\circledR}\right)\right]$ para detecção de coliformes totais e E. coli em água.

À medida que os coliformes se reproduzem em presença Colilert, utilizam ß-galactosidase para metabolizar o indicador de nutriente orto-nitrofenol-beta-galacto- piranosideo (ONPG) e alterá-lo de incolor para amarelo. O E. coli usa ß-glucuronidase para metabolizar methyl-umbelipheril-glucuronide (MUG) e criar fluorescência. elemento químico emita energia em múltiplos comprimentos, na técnica de ICP-OES é mais comum a seleção de um único comprimento (ou alguns) para determiná-lo (Rocha 2007).
Já que a maioria dos não coliformes não conta com estas enzimas, não pode se reproduzir e interferir. Os poucos não coliformes que têm estas enzimas são seletivamente suprimidos pela matriz especificamente formulada do Colilert. Esta abordagem diminui a incidência de falso-positivos e falso-negativos.

Assim, adiciona-se o reagente próprio à amostra, misturando bem. Após isso se deposita na cartela Quanti-Tray ${ }^{\circledast / 2000}$ e a lacra, colocando depois em uma incubadora por 24 horas a uma temperatura de $35^{\circ} \mathrm{C}$. Após isso, contam-se as cavidades amarelas e as que apresentam fluorescência sob luz ultravioleta, consultando tabela de número mais provável (NMP), para determinar o número mais provável de coliformes totais e E. coli.

\subsection{Preparação das amostras de sedimento}

No Laboratório de Saneamento Ambiental da Escola de Minas, as amostras foram colocadas em bacias plásticas, tampadas com papel e secas ao natural a fim de garantir que o máximo de umidade fosse removida. Elas ainda foram levadas à estufa, na temperatura de $60^{\circ} \mathrm{C}$.

Após a secagem, as amostras de sedimento foram quarteadas e peneiradas no Laboratório de Sedimentologia do DEGEO, utilizando-se peneiras com malhas $9,16,32,60$, 115, 250 e >250 mesh, obtendo-se frações granulométricas
$500,210,149,63$ e $<63 \mu \mathrm{m}$, respectivamente. Como se trata de um estudo ambiental, a fração $<63 \mu \mathrm{m}$ foi utilizada para as análises químicas das amostras de sedimento, considerando que vários estudos indicam que os metais e metaloides estão preferencialmente associados às frações mais finas (Förstner 2004).

A fração a ser utilizada para a análise química de digestão parcial foi levada à estufa novamente por duas horas a fim de se garantir a sua secagem.

\subsection{Análises químicas das amostras de sedimento}

Para a digestão das amostras de sedimento foi usado o método de digestão ácida parcial com água régia, seguindo o procedimento padrão adotado pelo LGqA/ DEGEO/UFOP. As amostras de sedimento foram analisadas por ICP-EOS.

$\mathrm{Na}$ digestão parcial, depois de peneiradas e secas em estufa, pesou-se $1 \mathrm{~g}$ de amostra, que foi transferida para o interior de um bequer de $100 \mathrm{~mL}$. Em seguida, adicionou-se 7 $\mathrm{mL}$ de ácido clorídrico $\mathrm{HCL}$ e 2,3 $\mathrm{mL}$ de ácido nítrico $\mathrm{HNO}_{3}$.
Deixou-se repousar durante 16 horas à temperatura ambiente para permitir a oxidação lenta da matéria orgânica do sedimento. Em seguida, as amostras foram colocadas sobre placa aquecedora a $110^{\circ} \mathrm{C}$ por cerca de 2 horas. Esfriaram lentamente para a temperatura ambiente $\mathrm{E}$ foram filtradas com membranas de filtro de celulose com $8 \mu \mathrm{m}$ de porosidade, recolhendo o filtrado e completando o volume de $100 \mathrm{~mL}$ com água milli-Q. Em seguida, foram levadas para análises pelo ICP-EOS.

\subsection{Base legal do instrumento de enquadramento dos corpos de água}

Segundo Resolução do Conselho Nacional de Meio Ambiente (CONAMA) 357/2005, em seu artigo 42, enquanto não aprovados os respectivos enquadramentos, as águas doces serão consideradas classe 2 , exceto se as condições de qualidade atuais forem melhores, o que determinará a aplicação da classe mais rigorosa correspondente. Nesta mesma Resolução, atualizada pela CONAMA 430/2011, foram propostas os limites a serem comparados durante o trabalho.

Assim, como o Rio Oratórios e seus afluentes analisados não dispõem ainda de um enquadramento, foram considerados classe 2 para as discussões. 


\section{RESULTADOS E DISCUSSÕES}

\subsection{Análise das amostras e medições realizadas na água}

Considerando os resultados encontrados nas análises de temperatura, turbidez, condutividade elétrica/resistividade, STD, $\mathrm{pH}, \mathrm{OD}$ e POR realizadas durante o procedimento de campo, observamos que todos os pontos amostrais respeitaram a legislação ambiental para corpos d'água de classe 2, Resolução CONAMA 357/430, durante as realizações de coleta.

Nas análises de alcalinidade, o valor mínimo encontrado foi $14,70 \mathrm{mg} / \mathrm{L}$, e o máximo, $55,00 \mathrm{mg} / \mathrm{L}$. Nas de sulfatos, o máximo foi $12,96 \mathrm{mg} / \mathrm{L}$. Nas de cloretos, variou de 2,50 a 29,74. Dessa forma, todos os valores encontrados respeitaram a legislação ambiental. Além disso, pelo fato de estarem bem abaixo da norma, é plausível inferirmos que esse corpo hídrico recebe baixa carga de efluentes que interfiram nesses parâmetros.

Os valores de Demanda Química de Oxigênio (DQO) encontrados no Rio Oratórios foram elevados, variando de 6,6 a $138 \mathrm{mg} / \mathrm{L}$, mostrando que o consumo de oxigênio nas águas é alto. Concluímos, então, que o corpo hídrico recebe interferência. Como foi realizada apenas a análise de DQO, não podemos deduzir se essa carga despejada no rio é biodegradável ou não, pois, por ela, toda substância orgânica ou inorgânica que pode ser oxidada quimicamente (dicromato) contribui para a demanda química de oxigênio, caracterizando, portanto, uma medida indireta de consumo de $\mathrm{O}_{2}$.

Nos resultados dos parâmetros biológicos observamos que praticamente todo o corpo hídrico encontra-se comprometido, com a maioria dos pontos com valores acima de 2.420 coliformes termotolerantes por $100 \mathrm{~mL}, 2,4$ vezes superior ao limite da legislação. Em apenas um ponto de amostragem, FLRO 11, os valores foram respeitados durante todas as análises, fato exigido pela CONAMA 357/430, e, mesmo assim, chegaram perto do limite durante uma das coletas, com 920 coliformes termotolerantes por $100 \mathrm{~mL}$, enquanto a legislação permite até 1.000 coliformes termotolerantes por $100 \mathrm{~mL}$. A partir dos resultados, estabelecemos indiretamente que esse corpo hídrico recebe efluente de esgotos domésticos — o fato foi comprovado durante as observações de campo, quando notamos o despejo direto de residências ribeirinhas e da presença de animais (gado e porcos) até mesmo dentro do rio.

Dentre os elementos analisados na água, o cálcio, o enxofre, escândio, estrôncio, ítrio, magnésio, molibdênio, potássio, silício, sódio e o tálio não apresentam legislação específica, contendo valores de referência para esses elementos.

Em relação ao arsênio, cádmio e chumbo, elementos de transição de elevada toxicidade, mesmo existindo legislação que trate a respeito desses elementos, ressaltamos que não foi possível fazer nenhuma análise dos mesmos, pois o limite de detecção do aparelho era superior ao da lei e todas as medições ficaram abaixo do limite de detecção.

Os elementos bário, que variou de 12,5 a 41,4 $\mu \mathrm{g} / \mathrm{L}$; berílio, abaixo do limite de quantificação em todos os pontos; cobre, de abaixo do limite de quantificação a $8,8 \mu \mathrm{g} / \mathrm{L}$; cobalto, abaixo do limite de quantificação em todos os pontos; cromo, abaixo do limite de quantificação em todos os pontos; fósforo, de abaixo do limite de quantificação a $0,39 \mathrm{mg} / \mathrm{L}$; lítio, abaixo do limite de quantificação em todos os pontos; níquel, abaixo do limite de quantificação em todos os pontos; vanádio, abaixo do limite de quantificação em todos os pontos; e zinco, que variou de abaixo do limite de quantificação a $13,7 \mu \mathrm{g} / \mathrm{L}$, respeitaram os limites da legislação em todas as amostras.

O alumínio variou de abaixo do limite de quantificação a $443 \mu \mathrm{g} / \mathrm{L}$. Em apenas 6 amostras de água — FLRO 01, 02, 04, 06, 08 e $09-$, originárias do $3^{\circ}$ trabalho de campo realizado no maior período chuvoso abarcado em nossa pesquisa, ele foi encontrado acima do limite exigido em lei, que é $100 \mu \mathrm{g} / \mathrm{L}$. Dessa maneira, podemos associar a sua presença devido à erosão e ao transporte de sedimentos pela chuva para o corpo hídrico. $\mathrm{Na}$ análise do ferro, detectamos concentração acima do limite da legislação pelo menos uma vez em todos os pontos amostrados. Na do manganês, concentração acima do limite da legislação pelo menos uma vez em nove pontos amostrais.

Os elevados valores de ferro, manganês e alumínio, nesses casos, podem ser associados principalmente à geologia do local, porquanto o solo da Bacia do Rio Oratórios apresenta altos valores desses elementos.

\subsection{Análise das amostras e medições realizadas no sedimento}

Dentre os elementos analisados nos sedimentos, o alumínio, berílio, bismuto, cálcio, enxofre, escândio, estrôncio, ferro, fósforo, ítrio, lítio, magnésio, manganês, potássio, silício, sódio, tálio, tório, vanádio e zircônio não apresentam legislação específica com valores de referência.

Inicialmente, sobre o antimônio não poderíamos fazer nenhuma inferência, pois o limite de quantificação é maior do que o de prevenção e os resultados ficaram abaixo desse valor. Todavia, usando o parâmetro de intervenção de Área de Proteção Máxima, que nesse caso é maior que o da prevenção, $5 \mathrm{mg} / \mathrm{kg}$ (valor que já seria visível na quantificação), concluímos que, em um cenário de exposição genérico, os sedimentos do Rio Oratórios não apresentam riscos potenciais diretos ou indiretos à saúde humana. Já os elementos arsênio, cádmio e molibdênio respeitaram os limites em todas as amostras.

O bário ultrapassou o limite da legislação em sete locais amostrados. Onde ele aparece em excesso, o solo não possui propriedades capaz de sustentar as suas funções primárias de proteger os receptores ecológicos e a qualidade das águas.

O chumbo apresentou apenas uma amostra fora dos limites da legislação. Frisamos que, em outra coleta realizada no mesmo local onde essa amostragem fora dos limites foi extraída, as análises apresentaram valores inferiores. Contudo, acreditamos que esse sítio amostral possa ter sofrido contaminação pontual, o que não significa que a qualidade do solo tenha sido afetada.

O cobre ficou além do limite da legislação em 11 locais amostrados. Onde ele aparece em excesso, o solo não possui qualidade capaz de sustentar as suas funções primárias de proteger 
os receptores ecológicos e as características das águas. A partir desses valores, podemos inferir indiretamente que esse elemento pode estar associado a produtos agrícolas como fungicidas e agroquímicos utilizados indevidamente no tratamento do solo.

O cobalto ficou além do limite da legislação em 12 locais amostrados. Onde ele aparece em excesso, o solo não registra qualidade capaz de sustentar as suas funções primárias de proteger os receptores ecológicos e as características das águas. Assim como o cobre, pode estar associado a produtos agrícolas.

O cromo ficou além do limite da legislação em todos os locais amostrados. Onde ele aparece em excesso, o solo não possui qualidade capaz de sustentar as suas funções primárias de proteger os receptores ecológicos e a qualidade das águas. $\mathrm{O}$ elemento pode contaminar o meio ambiente por meio de fertilizantes, assim como o cobre e o cobalto, mas também por meio da utilização em curtumes - observamos durante os trabalhos de campo, próximo às margens do rio, que existem matadouros de gado, o que evidencia a possível existência da atividade de curtimento de couro. $\mathrm{O}$ fato de o cromo ser encontrado em todos os pontos também pode estar associado à sua bioacumulação em longo prazo, visto que compostos como $\mathrm{Cr}$ não se decompõem ou apresentam baixa degradabilidade, sendo acumulados no meio ambiente (Jordão et al. 1999).

O níquel ficou além do limite da legislação em nove locais amostrados. Onde ele aparece em excesso, o solo não possui qualidade capaz de sustentar as suas funções primárias de proteger os receptores ecológicos e as características das águas.

O zinco ficou além do limite da legislação em dois locais amostrados. Onde ele aparece em excesso, o solo não possui qualidade capaz de sustentar as suas funções primárias de proteger os receptores ecológicos e o padrão das águas. Assim como o cobre e o cobalto, pode estar associado a produtos agrícolas.

\subsection{Classificação das Águas segundo Berner \& Berner}

Os pesquisadores Berner e Berner (1987) propuseram, em seu livro clássico The global water cycle, uma classificação de rios apoiando-se em um diagrama em forma de bumerangue que até hoje é usado com grande sucesso. Segundo os autores, uma das razões para se classificar um rio é determinar quais dos fatores (ou mecanismos) ambientais naturais afetam a química de suas águas. Assim, por meio de estudos de rios bem conhecidos, pode-se extrapolar os resultados para aqueles são menos. Esta classificação foi baseada em Gibbs (1970). O diagrama está apresentado na Figura 2.

Os principais mecanismos naturais que interferem na química das águas superficiais do mundo são:

- precipitação atmosférica, tanto na composição quanto na quantidade;

- domínio litológico, intemperismo das rochas;

- evaporação e cristalização fracionada.
Assim, foi proposto por Berner e Berner (1987) um diagrama na forma de um bumerangue, plotando-se a concentração de Sódio $(\mathrm{Na})$, dividido pela concentração de dois cátions principais nas águas superficiais do mundo, $\mathrm{Ca}^{++}$e $\mathrm{Na}^{+}$, como na fórmula: concentração $\mathrm{Na} /(\mathrm{Na}+\mathrm{Ca})$, eixo X, versus total de STD, eixo Y. Os rios são posicionados nos três cantos do bumerangue, que representam as áreas dominadas por cada um dos três mecanismos, ou em áreas intermediárias, nas quais mais de um mecanismo influencia a sua composição.

Contudo, conforme dados obtidos no rio e ilustrados na Figura 2, pode-se constatar que o Rio Oratórios é controlado principalmente pelo seu ambiente litológico, sendo importante entender a correlação que possa existir entre as possíveis poluições encontradas e a litologia local.
Figura 2

Caracterização dos rios baseados no diagrama de Berner e Berner (1996), com destaque para os rios estudados na Bacia do Rio Doce.

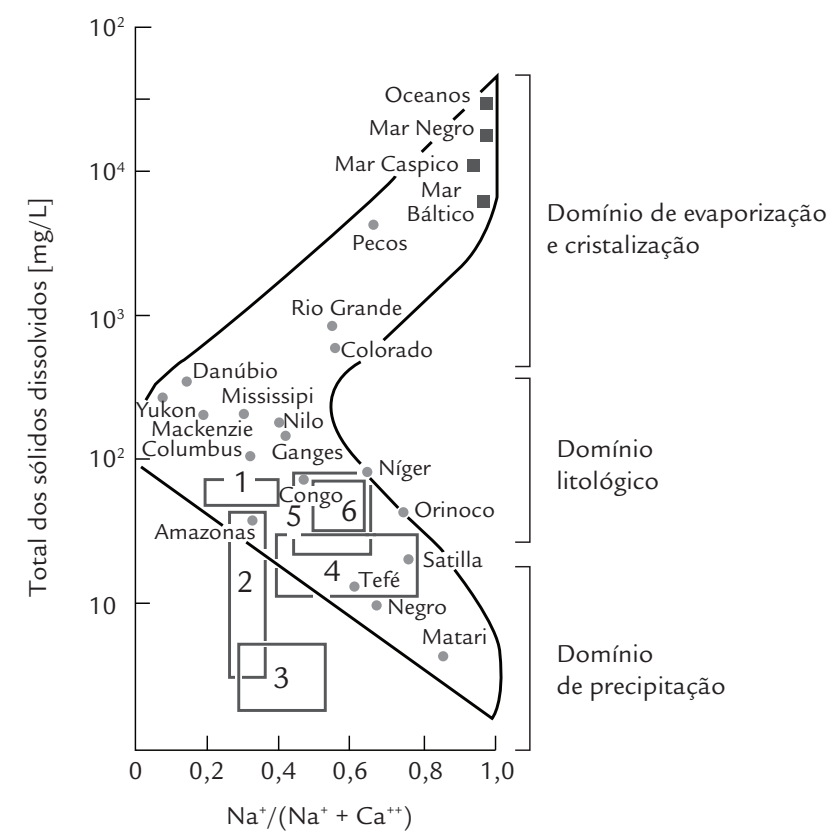

1: Barragem de Peti; 2: Rio Conceição; 3: Rio Caraça; 4: Rio Piracicaba; 5: Rio Piranga; 6: Rio Oratórios. 


\section{CONCLUSÕES}

Durante o desenvolvimento desta pesquisa realizamos estudos físicos, químicos, biológicos e geoquímicos em amostras de água e sedimentos de fundo para avaliar a qualidade e os impactos ambientais na Bacia do Rio Oratórios.

Os parâmetros físico-químicos $(\mathrm{pH}$, temperatura, oxigênio dissolvido, condutividade elétrica, resistividade, TDS, ORP, turbidez, alcalinidade, sulfato e cloreto) apresentaram valores dentro da normalidade, em conformidade com as postulações da legislação ambiental.

Considerando o uso prioritário da Bacia do Rio Oratórios para abastecimento público, os parâmetros analisados deveriam se enquadrar como classe 2 , de acordo com a Resolução CONAMA 357/05 e 430/11. Dessa maneira, alguns dos itens, demonstrados no tópico no qual discutimos os resultados de nossas análises, ultrapassaram esses limites máximos, o que nos leva a concluir que a bacia hidrográfica estudada precisa receber medidas iminentes para que os problemas encontrados sejam sanados. Para o melhor aproveitamento dos recursos hídricos daquela região é necessário que pesquisas mais aprofundadas, com o intuito de identificar os focos poluidores, sejam realizadas.

Destacamos ainda que, por conta da sazonalidade das amostras examinadas, os resultados foram compatíveis com o período. Houve apenas um caso em que um foco de contaminação pode ser colocado como pontual (no caso, o chumbo encontrado nos sedimentos). Já nas demais ocorrências, as sazonalidades dos resultados mostraram que as contaminações existentes são, em sua maioria, contínuas.

A Bacia do Rio Oratórios está inserida tanto em conglomerados urbanos quanto em zonas rurais, o que permite que receba interferências antrópicas comum aos dois locais. Acerca das influências das zonas urbanas, observamos principalmente as causadas por razão do saneamento (problema comum também em regiões rurais), não constatando grandes interferências de indústrias nos resultados apresentados.

Dentre as influências das zonas rurais, assinalamos o uso de produtos agrícolas uma vez que, durante os trabalhos de campo, verificou-se a sua aplicação sem os devidos cuidados. Além disso, os resultados obtidos para cromo, cobre, cobalto e zinco apontaram para a possível presença de tais utilizações.

Embora a maior parte dos parâmetros esteja dentro dos limites estabelecidos pela legislação, medidas de recuperação ambiental precisam ser adotadas. Assim como na Bacia Hidrográfica do Rio Doce, o potencial de desenvolvimento da região do Oratórios é significativo, especialmente se avaliarmos a disponibilidade de seus recursos naturais, fator que realça a importância de planos e projetos de gestão da bacia, a fim de permitir o desenvolvimento sustentável da região e evitar a sua degradação contínua.

Por meio das muitas análises realizadas, encontramos resultados que evidenciaram a contaminação do Rio Oratórios por efluentes domésticos e, possivelmente, por agrotóxicos. Contudo, inferimos que a utilização direta da água do corpo hídrico não é apropriada. No momento, como ainda não existe a implementação de um projeto ambiental preciso, a água do Rio Oratórios deve ser evitada ou tratada imediatamente, dependendo de qual será o seu uso.

\section{REFERÊNCIAS}

Agudo E.G. 1987. Guia de coleta e preservação de amostra de água. CETESB, São Paulo, 150 p.

AMM. Associação Mineira de Municípios. 2012. Cidades. Disponível em: http://campanhadigital.net.br/minas_de_a_z/minas/\#.VL1pZkfF-BA. Acessado em 25 fev 2012.

Benevides V.F.S., Beekman G.B. 1995 Aspectos de sustentabilidade e vulnerabilidade dos recursos hídricos. In: Anais, Simpósio Brasileiro Recursos Hídricos, Recife, Nov 1, p.51-55.

Berner E.K., Berner R.A. 1987. The global water cycle: geochemistry and environment. Englewood Cliffs: Prentice-Hall, New Jersey, 397 p.

Brasil. Agência Nacional de Águas. 2006. A evolução da gestão dos recursos hídricos no Brasil. Disponível em: http://www.ana.gov.br/AcoesAdministrativas/ CDOC/cdoc3.asp Acessado em 30 abr 2011.

Brasil. Ministério do Meio Ambiente. Conselho Nacional do Meio Ambiente. 2000. Resolução CONAMA no 274, de 29 de novembro de 2000. Define os critérios de balneabilidade em águas brasileiras. Brasília: Diário Oficial da União. 
Brasil. Ministério do Meio Ambiente. Conselho Nacional do Meio Ambiente. 2005. Resolução CONAMA no 357, de 17 de março de 2005. Dispõe sobre a classificação dos corpos de água e diretrizes ambientais para o seu enquadramento, bem como estabelece as condições e padrões de lançamento de efluentes, e dá outras providências. Brasília: Diário Oficial da União.

Brasil. Ministério do Meio Ambiente. Conselho Nacional do Meio Ambiente. 2011. Resolução CONAMA n ${ }^{\circ} 430$, de 13 de maio de 2011. Dispões sobre as condições e padrões de lançamento de efluentes, complementa e altera a Resolução n ${ }^{\circ}$ 357, de 17 de março de 2005, do Conselho Nacional do Meio Ambiente-CONAMA. Brasília: Diário Oficial da União.

Cruz L.V.2002. Avaliação geoquímica ambiental da Estação Ecológica do Tripuí e adjacências, Sudeste do Quadrilátero Ferrífero, MG. Dissertação de Mestrado, Departamento de Geologia, Universidade Federal de Ouro Preto, 147 p.

Derisio J.C. 2000. Introdução ao controle de poluição ambiental. Signus, São Paulo, $201 \mathrm{p}$.

Faria J.L. 2004. Conflitos e participação da sociedade civil na instalação do Comitê de Bacia Hidrográfica do Rio Doce. Dissertação de Mestrado, Departamento de Economia Rural, Universidade Federal de Viçosa, 145 p..

Feldmann F. 1992. Guia da ecologia: para entender e viver melhor a relação homem natureza. Abril, São Paulo, 320 p.

Förstner U. 2004. Traceability of sediments analysis. Trends in Analytical Chemistry, 23:217-236.

Greenberg A.E., Clesceri L.S., Eaton A.D. (eds.). 1992. Standard methods for the examination of water and wastewater. 18 ed. American Public Health Association, Washington, $1.496 \mathrm{p}$.

Gibbs R.J. 1970. Mechanism controlling world water chemistry. Science, 170:1088-1090.

IBGE. Instituto Brasileiro de Geografia e Estatística. 2007. Contagem de População 2007. Disponível em: http://www.cidades.ibge.gov.br/xtras/home. php. Acessado em 25 fev 2012.

Minas Gerais. Instituto Mineiro de Gestão de Águas. 2005. Aperfeiçoamento do monitoramento da qualidade das águas da Bacia do Alto Curso do Rio das Velhas. PNMA II, Belo Horizonte, 175 p.

Minas Gerais. Instituto Mineiro de Gestão de Águas. 2007. Plano integrado de recursos hídricos da Bacia do Rio Doce e dos planos de ações de recursos hídricos para as unidades de planejamento e gestão de recursos hídricos no âmbito da Bacia do Rio Doce. Item 4.6 - Poluição Industrial. Disponível em: http://www.riodoce.cbh.gov.br/PlanoBacia_PIRH-Doce.asp. Acessado em 25 mar 2012.

Jordão C.P., Silva A.C., Pereira J.L., Brune W. 1999. Contaminação por cromo de águas de rios provenientes de curtumes em Minas Gerais. Química Nova, 22:47.

Lacerda F.M. 2010. Caracterização da bacia hidrográfica do Rio Piranga: elaboração de um banco de dados como instrumento de gestão ambiental. Monografia, Escola de Minas, Universidade Federal de Ouro Preto, 177 p.

Lougon M.S., Louzada F.L.R.O, Rocha S.A., Garcia G.O., Santos A.R. 2009. Diagnóstico ambiental da Sub-Bacia Hidrográfica do Córrego Amarelo, abordando o uso e ocupação do solo e a qualidade de água. Engenharia Ambiental, 6:350-367.

Minas Gerais. (S/D) Instituto Mineiro de Gestão das Águas. 2011. Agências de Bacia. Belo Horizonte, MG, IGAM. Disponível em: http://comites.igam. mg.gov.br/comites-estaduais/bacia-do-rio-doce/do1-cbh-do-rio-piranga Acessado em 27 jan 2015.

Rocha G.P., Monteiro M.I.C., Carneiro M.C. 2007. Determinação de metais-traço por ICP-OES em amostras de minério. In: Anais, I Jornada do Programa de Capacitação Interna - CETEM. 
Romão A.C.B.C., Souza M.L. 2011. Análise do uso e ocupação do solo na Bacia do Ribeirão São Tomé, Noroeste do Paraná - PR (1985 e 2008). Ra’e Ga (UFPR), 21:337-364.

Setti A.A., Lima J.E.F.W., Chaves A.G.M., Pereira I.C. 2001 Introdução ao gerenciamento dos recursos hídricos. ANEEL/ANA, Brasília, 327 p.

Soares M.R.G.J., Souza J.L.M., Jerszurki D. 2011. Caracterização do meio físico e formas de uso e ocupação do solo da bacia do Rio Pequeno Paraná. Ra'e Ga (UFPR), 21:165-184.

Sociedade de Abastecimento de Água e Saneamento S/A. SANASA. 2013. Sociedade de Abastecimento de Água e Saneamento. Disponível em: http:// www.sanasa.com.br. Acessado em 10 abr 2013. 